\title{
High-Performance Control Technology of Buck Inverter Used for Super- Precision Machining of Composite Materials
}

\author{
En-Chih Chang ${ }^{*}$, Hung-Liang Cheng, and Chun-An Cheng \\ Department of Electrical Engineering, I-Shou University, Kaohsiung City, Taiwan, R.O.C.
}

\begin{abstract}
An effective technique, genetic-feedforward sliding mode-fractional PI controlled buck inverter used for super-precision machining of composite materials is proposed. The obstruction using sliding mode control (SMC) is due to the strong chattering that severely limits its practical applicability. The chattering yields high voltage distortion in buck inverter output, thus degrading stability and reliability of super-precision machining of composite materials. The modification structure to fractional PI has been established through the plant extending way so that the chattering is diminished and better flexibility in adjusting system response can be provided. The feedforward compensator improves the dynamics response further. The genetic algorithm (GA) can be adopted for determining optimal fractional proportional-integral (FPI) parametric values. With this control technique, the TI microprocessor-based buck inverter is implemented, and then experiments illustrate that the presented technique produces less steady-state inaccuracy, chattering attenuation, loading interference rejection and parametric variation removal.
\end{abstract}

\section{Introduction}

Super-precision machining of composite materials (such as aluminum matrix composite, Cu-based composite, and magnesium matrix composite materials) needs stable and high-quality power sources $[1,2]$, i.e., 1 . inverter wave shape with small amounts of total harmonic distortion even under rectifier loading. 2. rapid transience against step changes in load. 3. zero steadystate errors. High performance buck inverter can provide these requirements by employing closed-loop control techniques [3, 4]. Early works on inverter control can be found in literature, for example, PI control [5], multiple feedback strategy [6], dead-beat method [7], and Fourier approach [8]. Although above schemes have presented the satisfactory results, both the low total harmonic distortion of output voltage and fast transient response cannot simultaneously be achieved. The SMC is capable of making a control system robust against internal parameter variations and external load disturbances [9, 10]. A number of SMC method developed for inverters has been done $[11,12]$. However, it is a pity that the chattering always exists. The chattering may damage inverter parts and cause highly distorted wave shape even if a SMC had incorporated a feedforward path so as to improve the dynamics response [13]. This study develops a plant extending architecture for designing feedforward sliding mode-fractional PI (FSM-FPI) controller with reduced chattering and higher flexibility. A FSM output becomes the plant input that is unable to endure a chatter. In order to overcome the chattering, a fractional-order extended plant, which implies the FPI is introduced [14-16]. Henceforth, the chattering happens at the input of the extended plant. Such chattering locates at system lower powered zone and therefore is inoffensive. It's important to note that optimal FPI parametric values maybe not easy for selection in the presence of various perturbations [17-26]. A GA conception firstly developed in 1975 by John Holland of the University of Michigan [27]. Then, De. Jong expands its application in function optimum [28-32]. The FPI parametric optimum is capable of obtaining determination via GA. Using proposed method, a buck inverter is very suitable for the application of superprecision machining of composite materials, yielding many advantages, such as low total harmonic distortion wave shape, satisfactory voltage regulation, reduced chattering, reduced steady-state inaccuracy and highaccuracy of the super-precision machining.

\section{Problem statement}

Consider the design of a SMC for controlled system below.

$$
\dot{\tilde{x}}=A \widetilde{x}+b u+f
$$

where $\tilde{x}$ symbolizes vector of variable errors, $A$ denotes state transition matrix, $b$ represents input matrix, $u$ stands for control input to the system, and $f$ signifies the disturbance.

The $\tilde{x}$ is given by

$$
\tilde{x}=x_{d}-x
$$

Corresponding author: enchihchang@isu.edu.tw 
where $x_{d}$ and $x$ is the vector of references and state vector, respectively.

The sliding surface governs the dynamic system that can be given by

$$
\sigma=c \tilde{x}
$$

where $c$ is constant.

A SMC control law is

$$
u=u_{f}+u_{e q}+u_{s}
$$

where $u_{f}=$ feedforward compensation control, $u_{e q}=$ equivalent control, and $u_{s}=$ switching control.

The dynamics in sliding action is defined as

$$
\dot{\sigma}=c \dot{\vec{x}}=0
$$

From (1) and (5), the equivalent control can be obtained as

$$
u_{e q}=-(c b)^{-1} c A \widetilde{x}
$$

By the use of the $\sigma \dot{\sigma}<0$, the switching control can be derived as

where $\rho>0$.

$$
u_{s}=-(c b)^{-1} \operatorname{\rho sgn}(\tilde{\alpha x})
$$

Evidently, the (7) uses an sgn function, the chattering will occur in practice. One solution reduces the chattering by means of section 3 design.

\section{Control technology design}

Suppose a control-system dynamics be

$$
\dot{x}=A x+b u+f
$$

where $x$ signifies a vector of system state, $A$ stands for a state transition matrix, $b$ represents an input matrix, $u$ denotes a control input, and $f$ is the disturbance.

To generate the expanded system states, a new vector can be constructed as

$$
\dot{x}=\Psi
$$

where $\Psi$ is a vector.

Substituting (9) into (8) yields

$$
\Psi=A x+b u+f
$$

The $u$ is designed in the following.

$$
u=\left(\left(K_{p} s^{\lambda}+K_{i}\right) \frac{1}{s^{\lambda}}\right) \tilde{x}
$$

where $k_{p}$ and $k_{i}$ stand for two gains.

Hence, there is a relationship as follows:

$$
\frac{u}{u_{a}}=\frac{1}{s^{\lambda}}
$$

where a FPI architecture can be written as

$$
u_{a}=\left(K_{p} s^{\lambda}+K_{i}\right) \tilde{x}
$$

From (2) and (9)-(13), the error equations are formulated by

$$
\begin{aligned}
& \dot{\tilde{x}}=\dot{x}_{d}-\Psi \\
& \ddot{\tilde{x}}=A^{2} \tilde{x}-A b u-b u_{a}-A^{2} x_{d}+\ddot{x}_{d}-A f-\dot{f}
\end{aligned}
$$

The sliding function of the extended system can be defined as

$$
\sigma=c \tilde{x}+\dot{\tilde{x}}
$$

where $c$ is constant

The following inequality can guarantee the existence of sliding mode

$$
\lim _{\sigma \rightarrow 0} \sigma \dot{\sigma}<0
$$

The conditions with $K_{p}$ and $K_{i}$ for satisfying (16) yield, and obviously the two parameters $K_{p}$ and $K_{i}$ are decided in a wide range. The optimum of the two parameters is sought blindly, and the local optimum may occur. In order to search the optimal parameters, a global optimum tool, namely, GA is employed for FSM-FPI controller.

The genetic algorithm procedure for FSM-FPI controller is outlined in the following.

1. Encoding two parameters $K_{p}$ and $K_{i}$.

2. Producing an initial generation.

3. Computing the fitness function.

4. Remaking current population through a selected mechanism.

5. Crossover is performed by a couple of members among new generation.

6. Using the mutation probability, the mutation is done in every number among new generation.

7. The maximum value of a fitness function is reserved in the old population to the current population.

8. Iteratively execute above steps until the acceptable solution appears.

\section{Design example}

For clarifying design technology in the section 3, a structure of a buck inverter is presented in Fig. 1 and its equivalence circuitry is plotted in Fig. 2. A load, which allows linearity or nonlinearity is tested so that buck inverter performance can be validated. A buck inverter output is design to track sine-reference $v_{r e f}$.

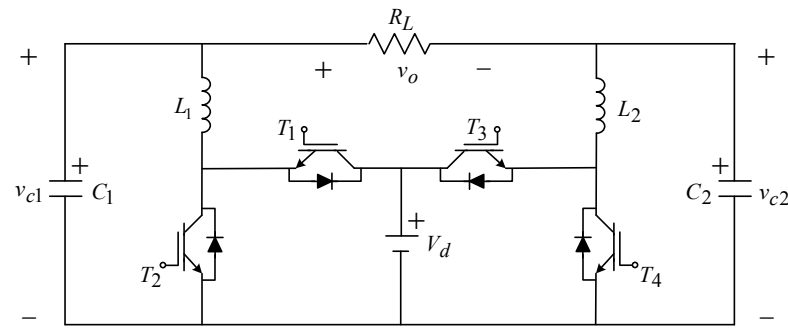

Fig. 1. Circuit diagram of buck inverter

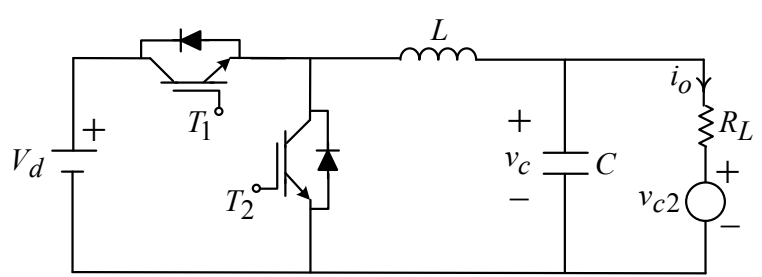

Fig. 2. Buck inverter's equivalence circuitry 
From the Fig. 1, the state space equation can be expressed as

$$
\left[\begin{array}{c}
\dot{v}_{c} \\
\ddot{v}_{c}
\end{array}\right]=\left[\begin{array}{cc}
1 & 0 \\
-\frac{1}{L C} & -\frac{1}{R_{L} C}
\end{array}\right]\left[\begin{array}{l}
v_{c} \\
\dot{v}_{c}
\end{array}\right]+\left[\begin{array}{c}
0 \\
\frac{V_{d}}{L C}
\end{array}\right] u+\left[\begin{array}{c}
0 \\
\frac{\dot{v}_{c 2}}{R_{L} C}
\end{array}\right]
$$

where $v_{c}=v_{c 1}, L_{1}=L$ and $C_{1}=C$.

Then, the error differential equations expressing the system yield

$$
\begin{gathered}
\tilde{x}_{1}=v_{r e f}-v_{c} \\
\dot{\tilde{x}}_{1}=\dot{v}_{r e f}-\dot{v}_{c}=\tilde{x}_{2} \\
\dot{\widetilde{x}}_{2}=\tilde{x}_{3}=\ddot{v}_{r e f}-\ddot{v}_{c} \\
=\ddot{v}_{r e f}-a_{1} \tilde{x}_{1}-a_{2} \tilde{x}_{2}-b u+N+\Gamma \\
\dot{\tilde{x}}_{3}=\dddot{v}_{r e f}-\dddot{v}_{c} \\
=\dddot{v}_{r e f}-a_{1} \tilde{x}_{2}-a_{2} \tilde{x}_{3}-b K_{p}\left(s{ }^{\lambda} \tilde{x}_{1}\right)-b K_{i} \tilde{x}_{1}+\dot{N}+\dot{\Gamma}
\end{gathered}
$$

where $a_{1}=\frac{1}{L C}, a_{2}=\frac{1}{R_{L} C}, b=\frac{V_{d}}{L C}, N=\frac{\dot{v}_{c 2}}{R_{L} C}$, and $\Gamma=a_{1} v_{r e f}+a_{2} \dot{v}_{r e f}+\ddot{v}_{r e f}$.

The sliding surface is chosen as

$$
\sigma=m_{1} \tilde{x}_{1}+m_{2} \tilde{x}_{2}+\tilde{x}_{3}
$$

where $m_{1}$ and $m_{2}$ are constants.

Then,

$$
\begin{aligned}
\dot{\sigma}= & m_{1} \tilde{x}_{2}-m_{2} a_{1} \tilde{x}_{1}-m_{2} a_{2} \tilde{x}_{2}-b u++N+\Gamma \\
& -a_{1} \tilde{x}_{2}-a_{2} \tilde{x}_{3}-b K_{p}\left(s \tilde{x}_{1}\right)-b K_{i} \tilde{x}_{1}++\dot{N}+\dot{\Gamma}
\end{aligned}
$$

where $a_{1}=a_{10}+\Delta a_{1} \quad, \quad a_{2}=a_{20}+\Delta a_{2} \quad$ and $b=b_{0}+\Delta b$.

Redefine the control function $u_{e x}$ as

$$
u_{e x}=u_{e x_{-} f}+u_{e x_{-} e q}+u_{e x_{-} s}
$$

The equivalent control $u_{e x \_} e q$ is derived by underneath operation:

$$
\left.\dot{\sigma}\right|_{a_{1}=a_{10}, a_{2}=a_{20}, b=b_{0}, \Gamma=0}=0
$$

The feedforward compensator $u_{e x \_} f$ is employed to enhance the tracking performance as follows.

$$
\left.\dot{\sigma}\right|_{a_{1}=a_{10}, a_{2}=a_{20}, b=b_{0}, N=0}=0
$$

The sliding control $u_{e x_{-} s}$ is used to suppress the parameter variations and load disturbances that can be chosen as

$$
u_{e x_{-} s}=\Phi_{1} \tilde{x}_{3}+\Phi_{2}
$$

An inequality depicts sliding existence as follows:

$$
\sigma \dot{\sigma}<0
$$

Substituting (25)-(27) into (28), the parameters $K_{p}$, $K_{i}, \Phi_{1}$, and $\Phi_{2}$ will be obtained to satisfy the (28). To find the optimum parameters $K_{p}$ and $K_{i}$, the GA can be adopted for searching global optimization parameters. The process of optimizing the two parameters describes concretely as follows: (i) Two parameters should be encoded into a string of eight bits. (ii) An initial generation $P(0)=150$ is produced randomly. (iii) High crossover probability has fast search, and thus $P_{c}=0.8$. (iv) Generally, the probability of mutation is low, and therefore $P_{m}=0.045$. (v) Reserving maximum value of a fitness function in the old population to the current population. (vi) Once the seek time is enough long, the solution is obtained.

\section{Experimental results}

The robustness to buck inverter will be investigated via the experiments. The parameters of the buck inverter used for the proposed method display as Table 1.

\begin{tabular}{lc}
\multicolumn{2}{c}{ Table 1. System parameters } \\
\hline DC voltage & $200 \mathrm{~V}$ \\
Filter capacitor & $2 \mu \mathrm{F}$ \\
Filter inductor & $0.5 \mathrm{mH}$ \\
Switching frequency & $15 \mathrm{kHz}$ \\
Output voltage and frequency & $110 V_{r m s}, 60 \mathrm{~Hz}$ \\
\hline
\end{tabular}

Figure 3 shows the proposed method under a resistive load $12 \Omega$ condition. For the purpose of testing transience further, the step-changing load circumstances while the resistive load is abruptly connected, as shown in Fig. 4. We can find that the developed buck inverter has slight voltage droop and then rapid retrieve in face of step-changing load. A nonlinear load is composed of a full-wave rectified with a parallel resistor, $35 \Omega$ and capacitor filter, $270 \mu \mathrm{F}$. Although load current shown in Fig. 5 is distorted highly, the output-voltage wave shape for the presented technique exhibits a low voltage $\%$ THD (total harmonic distortion) of $1.16 \%$. Fig. 6 illustrates that the developed buck inverter can allow random variations of LC filter parameters, from $15 \%$ to $250 \%$ of nominal values in the presence of resistive load $12 \Omega$. The phase plane of the proposed method under nonlinear load is shown in Fig. 7. It is very clear that the proposed technique effectively not only alleviates the chatter but also improves transient response due to the feedforward compensator.

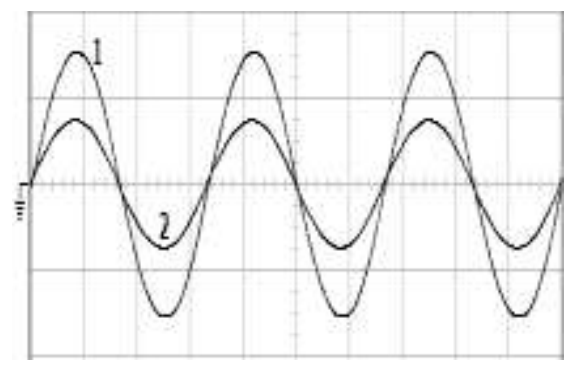

Fig. 3. Waveforms under rated load (1: voltage; 2: current) (vert.: $100 \quad$ Volts/division and 20Ampere/division, hor.: $5 \mathrm{msec} /$ division) 


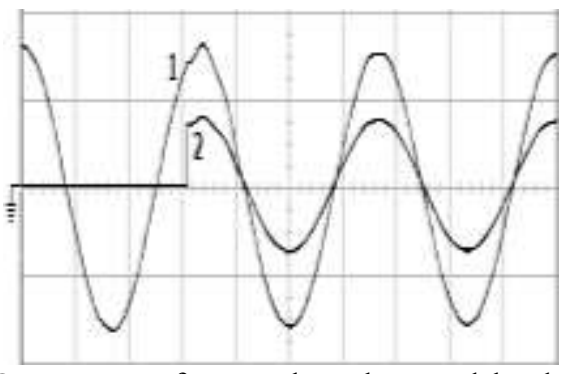

Fig. 4. Output waveforms when the rated load abruptly applied (1: voltage; 2: current) (vert.: 100 Volts/division and 20Ampere/division, hor. : $5 \mathrm{msec} /$ division)

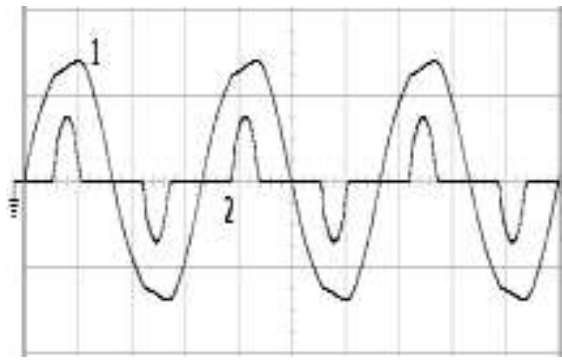

Fig. 5. Waveforms under nonlinear loading (1: voltage; 2: current) (vert.: $100 \quad$ Volts/division and 20Ampere/division, hor. : $5 \mathrm{msec} /$ division)

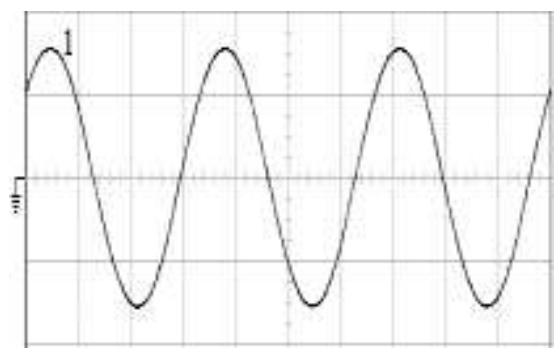

Fig. 6. Wave shape against LC parametric variations (1: voltage) (vert.: 100 Volts/division, hor.: $5 \mathrm{msec} /$ division)

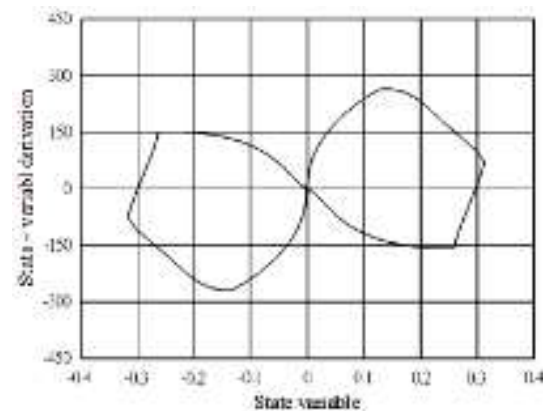

Fig. 7. Phase plane for the proposed method

\section{Conclusions}

This study has proposed genetic-feedforward sliding mode-fractional PI controller suitable for buck inverter used in super-precision machining of composite materials, to improve the dynamic response, to alleviate the chattering, to optimize the FPI parameters and to enhance machining stability. FSM not only has the merits of SMC but also improves the dynamics response by feedforward compensator. The extended plant method alleviate the chattering due to the FPI combined FSM. Furthermore, the GA is employed in FSM-FPI controller to optimize the FPI parameters. Thus, the buck inverter yields the good voltage regulation, fast dynamic response, and low THD output voltage. According to the experimental results and theoretic analysis, the proposed buck inverter is successfully demonstrated, thus supplying the reliability of super-precision machining of composite materials.

\section{Acknowledgment}

The authors would like to thank the Ministry of Science and Technology, Taiwan, R.O.C. for financially supporting this research under Contract No. MOST 1072221-E-214-006.

\section{References}

1. A. Ochsner, and H. Altenbach, Machining, Joining and Modifications of Advanced Materials, Springer, 2016.

2. J. P. Davim, Machining of Metal Matrix Composites, Springer, 2012.

3. R. Yuriy, R. Sergey, C. Evgeny, and V. Pavel, Power electronics basics: operating principles, design, formulas, and applications, CRC Press, Boca Raton, FL, USA, 2016.

4. H. Ma, and S. L. Han, "Buck inverter with sliding mode control strategy", in Proceedings of the 2004 IEEE Industrial Electronics Conference, 2004, pp.592-597.

5. H. I. Cha, S. S. Kim, M. G. Kang, and Y. H. Chung, "Real-time digital control of PWM inverter with PI compensator UPS," in Conf. Rec. IEEEIAS Annu. Meeting, 1990, pp. 1124-1128.

6. S. L. Jung, H. S. Huang, M. Y. Chang, and Y. Y. Tzou, "DSP-based multiple-loop control strategy for single-phase inverters used in ac power sources," IEEE PESC'97, vol. 1, 1997, pp. 706712.

7. A. Kawamura, T. Haneyoshi, and R. G. Hoft, "Dead beat controlled PWM inverter with parameter estimation using only voltage sensor," in Proc. IEEE PESC'86, 1986, pp. 576-583.

8. A. V. Jouanne, P. N. Enjeti, and D. J. Lucas, "DSP control of high-power UPS system feeding nonlinear loads," IEEE Trans. Ind. Electron., vol. 43, pp.121-125, 1996.

9. U. Itkis, Control systems of variable structure. New York: Wiley, 1976.

10. K. D. Young, V. I. Utkin, and U. Ozguner, "A control engineer's guide to sliding mode control," IEEE Trans. Contr. Syst. Technol., vol. 7, pp. 328342, 1999.

11. S. Vaidyanathan, and C. H. Lien, Applications of Sliding Mode Control in Science and Engineering, Springer, New York, 2017.

12. G. Bartolini, L. Fridman, A. Pisano, and E. Usai, Modern Sliding Mode Control Theory, SpringerVerlag, Berlin, 2008.

13. S. L. Jung, and Y. Y. Tzou, "Discrete feedforward sliding mode control of a PWM inverter for 
sinusoidal output waveform synthesis," in Proc. IEEE PESC'94, 1994, pp.552-559.

14. I. Podlubny, "Fractional-order Systems and $\mathrm{PI}^{\lambda} \mathrm{D}^{\mu}-$ Controllers," IEEE Transactions on Automatic Control, vol. 44, no. 1, pp. 208-214, 1999.

15. C. N. Zhao, and X. D. Zhang, "The Application of Fractional Order PID Controller to Position Servomechanism," Proc. World Congress on Intelligent Control and Automation, 2008, pp. 3380-3383.

16. H. M. Fan, Y. Sun, and X. B. Zhang, "Research on Fractional Order Controller in Servo Press Control System," Proc. Int. Conf. Mechatronics and Automation, 2007, pp. 2934- 2938.

17. I. Podlubny, L. Dorcak, and I. Kostial, "On Fractional Derivatives, Fractional-order Dynamic Systems and $\mathrm{PI}^{\lambda} \mathrm{D}^{\mu}$-Controllers," Proc. Int. Conf. Decision and Control, Vol. 5, 1997, pp. 4985-4990.

18. I. Podlubny, "Geometric and Physical Interpretation of Fractional Integration and Fractional Differentiation," Fractional Calculus and Applied Analysis, Vol. 5, No. 4, 2002, pp. 367386.

19. Y. Q. Chen; I. Petras, and D. Xue, "Fractional Order Control- A Tutorial," Proc. Int. Conf. American Control Conference, 2009, pp. $1397-$ 1411.

20. Q. S. Zeng, G. Y. Cao, and X. J. Zhu, "The Effect of the Fractional-order Controller's Orders Variation on the Fractional-order Control Systems," Proc. Int. Conf. Machine Learning and Cybernetics, 2002, pp. 367-372.

21. C. Ma, and Y. Hori, "Fractional Order Control and Its Application of $\mathrm{PI}^{\alpha} \mathrm{D}$ Controller for Robust TwoInertia Speed Control," Proc. Int. Conf. Power Electronics and Motion Control, Vol. 3, 2004, pp. 1477-1482.

22. C. B. Ma, and Y. Hori, "Backlash Vibration Suppression in Torsional System Based on the Fractional Order Q-Filter of Disturbance Observer," Proc. IEEE Int. Workshop Advanced Motion Control, 2004, pp. 577-582.

23. N. M. F. Ferreira, and J. A. T. Machado, "Fractional-Order Hybrid Control of Robotic Manipulators," Proc. Int. Conf. Advanced Robotics, 2003, pp. 393-398.

24. I. Petras, and B. M. Vinagre, "Practical Application of Digital Fractional-Order Controller to Temperature Control," Acta Montanistica Slovaca, Vol. 7, No. 2, 2002, pp. 131-137.

25. F. C. Clark, "PID algorithms and their computer implementation," IEEE Trans. Inst. Meas. Contr., vol. 6, pp. 305-316, 1984.

26. W. K. Ho, K. W. Lim, and W. Xu, "Optimal gain and phase margin tuning for PID controllers," Automatica, vol. 34, pp. 1009-1014, 1998.

27. J. H. Holland, Adaptation in Natural and Artificial Systems. Ann Arbor, Michigan: The University of Michigan Press, 1975.

28. T. R. Smith, and K. A. De Jong, "Genetic algorithms applied to the calibration of an information driven model of us migration patterns," in Proc. Conf. Modeling and Simulation, 1981, vol. 12, pp. 955-959.

29. K. A. De Jong, W. M. Spears, and D. F. Gordon, "Using genetic algorithm for concept learning," in Proc. Conf. Machine Learning, 1993, vol. 13, no. 2, pp. 161-188.

30. M. A. Ahmed, and K. A. De Jong, "Function approximator design using genetic algorithms," in Proc. Conf. IEEE Evol. Comput., 1997, pp. 519524.

31. S. N. Sivanandam, and S. N. Deepa, Introduction to Genetic Algorithms, Springer, 2008.

32. Kramer, Genetic Algorithm Essentials, Springer, 2017. 